\title{
Ginsenoside Rg3 attenuates myocardial ischemia/reperfusion injury via Akt/endothelial nitric oxide synthase signaling and the B-cell lymphoma/B-cell lymphoma-associated $X$ protein pathway
}

\author{
YIPING WANG, ZHAOHUI HU, BING SUN, JIAHONG XU, JINFA JIANG and MING LUO \\ Department of Cardiology, Tongji Hospital of Tongji University, Shanghai 200065, P.R. China
}

Received April 26, 2014; Accepted January 7, 2015

DOI: $10.3892 / \mathrm{mmr} .2015 .3336$

\begin{abstract}
Previous studies have suggested that ginsenoside Rg3 (GSRg3) extract from the medicinal plant Panax ginseng, may increase nitric oxide production via increases in the phosphorylation and expression of endothelial nitric oxide synthase (eNOS). The present study used an in vitro neonatal rat cardiomyocyte (NRC) model of anoxia-reoxygenation injury and an in vivo rat model of myocardial ischemia/reperfusion (MI/R) injury. Hemodynamic, histopathological and biochemical assessment of the myocardial injury was performed and the expression levels of lactate dehydrogenase (LDH), superoxide dismutase and creatine kinase $(\mathrm{CK})$ were measured in serum from the animal model, which may reflect myocardial injury. NRC injury was determined using a Cell Counting kit-8. The GSRg3 anti-apoptotic effects were assessed using flow cytometry to investigate the number of early-late apoptotic cells and western blot analysis was performed to analyze the protein expression levels of caspase-3, caspase-9, B-cell lymphoma-2 (Bcl-2), phosphorylated (p-)Akt and eNOS. The results suggested that pretreatment with GSRg3 (60 mg/kg) significantly improved rat cardiac function, as demonstrated by increased left ventricular systolic pressure, heart rate and first derivative of left ventricular pressure. GSRg3 also reduced the size of the myocardial infarct and $\mathrm{LDH} / \mathrm{CK}$ levels in the blood following $\mathrm{MI} / \mathrm{R}$. In vitro investigations revealed that GSRg3 $(10 \mathrm{mM})$ decreased NRC apoptosis through inhibiting the activation of caspase- 3 and caspase-9, and increasing the expression levels of p-Akt, eNOS and the ratio of $\mathrm{Bcl}-2 / \mathrm{Bcl}-2$-associated $\mathrm{X}$ protein (Bax). Overall, the present study revealed that GSRg3 mediated a cardioprotective effect against MI/R-induced apoptosis via Akt/eNOS signaling and the Bcl-2/Bax pathway.
\end{abstract}

Correspondence to: Professor Ming Luo, Department of Cardiology, Tongji Hospital of Tongji University, 389 Xincun Road, Putuo, Shanghai 200065, P.R. China

E-mail: luoming06@163.com

Key words: ginsenoside $\operatorname{Rg} 3$, myocardial ischemia/reperfusion, cardioprotective effect

\section{Introduction}

There is evidence suggesting that myocardial ischemia (MI) is a major risk factor of myocardial infarction, which induces myocardial remodeling. The predominant morphological changes of ventricular remodeling are the exhibition of an infarction area, ventricular hypertrophy and ventricular expansion $(1,2)$. The mechanisms underlying ventricular remodeling remain to be fully elucidated, however, it is generally accepted that following myocardial injury, the molecules, cells and mechanisms change due to altered gene expression levels and the imbalance between cell apoptosis and proliferation, which is important in the entire disease process (1).

It is important to develop novel treatments to inhibit or slow the disease process to enable more time for subsequent treatment. Traditional Chinese medicine has gained increased attention for the treatment of various diseases. Although the use of Chinese medicine in the treatment of ventricular remodeling has been investigated only relatively recently, it has been demonstrated that using traditional Chinese medicine can affect the occurrence and development of ventricular remodeling in a number of aspects (3). This is also supported by previous reports suggesting that certain agents, including statins, angiotensin converting enzyme inhibitors and angiotensin II receptor inhibitors, can improve ventricular remodeling by increasing cell apoptosis and preventing cell proliferation in smooth muscle cells in hypertensive animal models $(4,5)$.

Ginsenoside Rg3 (GSRg3), extracted from Panax ginseng, is a traditional Chinese herbal medicine used widely in clinical treatment and may significantly improve basilar artery hypertrophic remodeling through the prevention of artery smooth muscle cell proliferation (6). The present study predominantly investigated how GSRg3 attenuates MI/reperfusion (MI/R) injury and examined the main pathways involved.

\section{Materials and methods}

Animals and drugs. The present study was performed in accordance with the National Institutes for Food and Drug Control (http://www.nicpbp.org.cn) for the Use of Laboratory Animals and was approved by the Tongji Hospital of Tongji University (Shanghai, China) Committee on Animal Care. A total of 30 male eight-week-old Sprague-Dawley rats (Experimental Animal Center, Tongji University) weighing between 260 and $280 \mathrm{~g}$ 
were housed in diurnal lighting conditions ( $12 \mathrm{~h}$ light/12 h dark; $22-24^{\circ} \mathrm{C}$ ) and allowed free access to food and water for 7 days prior to performing the investigation. GSRg3 (purity $>98 \%$; Fig. 1) was purchased from the National Institute for the Control of Pharmaceutical and Biological Products (Beijing, China).

$M I / R$ procedure in the rat hearts. The cardial MI/R surgery was performed, as described previously (5). Briefly, the rats were anaesthetized via intraperitoneal injection of pentobarbital sodium (60 mg/kg body weight; Sigma-Aldrich, St. Louis, MO, USA) and were placed on a warm board $\left(25^{\circ} \mathrm{C}\right)$ to control the body temperature at $37^{\circ} \mathrm{C}$ for surgery. The neck was opened with a ventral midline incision and the animals were ventilated with room air using a rodent respirator (tidal volume $8 \mathrm{ml} / \mathrm{kg}$ body weight; 60-80 breaths/min; Shanghai Alcott Biotech Co., Ltd., Shanghai, China). An electrocardiogram in lead II was recorded through needle electrodes attached to the limbs. Following the adjustment of the respiratory rate and the tidal volume of gases, the chest was opened by a middle thoracotomy. Following pericardiotomy, a 4-0 black silk thread (Millar, Inc., Houston, TX, USA) was passed behind the left anterior descending coronary artery and was occluded by a knot for $30 \mathrm{~min}$ to cause ischemia. Subsequently, the knot was released and reperfusion was performed for $3 \mathrm{~h}$. For the sham control group, the black silk was placed under the left anterior descending coronary artery without occlusion.

Hemodynamic measurements. The right common carotid artery was exposed and cannulated with a Millar vessel (Millar, Inc.) into the left ventricular cavity of the rat through the ascending aorta. The heart function, including the left ventricular systolic pressure (LVSP), heart rate (HR) and first derivative $( \pm \mathrm{dp} / \mathrm{dt})$ of left ventricular pressure of the rats in each group (sham, I/R and $\mathrm{I} / \mathrm{R}+\mathrm{Rg} 3$ ) were recorded and programmed using a biotic signal collection and processing system (PowerLab; AD Instruments, New South Wales, Australia), as described previously (6).

Determination of the serum levels of SOD, LDH and $C K$. Following $3 \mathrm{~h}$ reperfusion, blood samples $(5 \mathrm{ml})$ were collected through the ventral aorta using a scalp vein set, and the serum was frozen at $-80^{\circ} \mathrm{C}$ until subsequent analysis. The activities of LDH, CK and SOD were determined using an ELISA kit, according to manufacturer's instructions (BioAssay Systems, Hayward, CA, USA).

Infarct size measurement. Following reperfusion, the hearts were rapidly extracted from the rats using surgical scissors and frozen at $-20^{\circ} \mathrm{C}$. The left ventricular area was sliced into six 2-3 mm-thick slices perpendicular to the base-apex and incubated in $2 \%$ triphenyltetrazolium chloride (TTC; pH 7.4; Xiya Reagent, Chengdu, China) buffer for $15 \mathrm{~min}$ at $37^{\circ} \mathrm{C}$. The viable tissues were stained dark red with TTC, while the infarcted portion remained grayish-white. The area of infraction was measured using an image analysis system [National Institutes of Health (NIH) image software, version 1.60; NIH, Bethesda, MA, USA]

Isolation of primary neonatal rat cardiomyocytes (NRCs) and anoxia-reoxygenation injury. Primary neonatal Sprague-Dawley rats (1-3 days-old) were purchased from the experimental
Animal center of Tongji University (Shanghai, China). Cardiac myocytes were cultured from 1-3 day-old Sprague-Dawley rats with Dulbecco's modified Eagle's medium (DMEM; Gibco Life Technologies, Carlsbad, CA, USA) at a density of $5 \times 10^{5}$ for three days, as described previously $(1,2)$. The primary neonatal rats were anaesthetized with sodium pentobartbital and decapitated, and then immersed in $75 \%$ ethanol $(20 \mathrm{ml})$ for $30 \mathrm{sec}$. The chest was opened and the heart ventricles were dissected rapidly and immersed in ice-cold Krebs-Ringer buffer containing $137 \mathrm{mM} \mathrm{NaCl}, 2 \mathrm{mM} \mathrm{CaCl} 2,5.4 \mathrm{mM} \mathrm{KCl}, 1.1 \mathrm{mM} \mathrm{MgCl}_{2} \cdot 6 \mathrm{H}_{2} \mathrm{O}$, $0.4 \mathrm{mM} \mathrm{NaH}_{2} \mathrm{PO}_{4} \cdot 2 \mathrm{H}_{2} \mathrm{O}, 11.9 \mathrm{mM} \mathrm{NaHCO}_{3}$ and $5.6 \mathrm{mM}$ glucose ( $\mathrm{pH}$ 7.4), and the ventricles were minced into small sections using eye scissors and digested with trypsin $(0.1 \%$; Beyotime Institute of Biotechnology, Guangzhou, China). The cardiomyocytes were cultured in DMEM containing $10 \%$ newborn calf serum (NCS; Gibco Life Technologies), in a humidified atmosphere of $95 \%$ air and $5 \% \mathrm{CO}_{2}$ at $37^{\circ} \mathrm{C}$. The neonatal rat cardiomyocytes (NRCs) were used and the ginsenoside-Rg3 and solvent were preincubated with cells for $30 \mathrm{~min}$ prior to I/R injury.

Simulated I/R (SI/R) was performed, as described previously $(1,2)$. Briefly, simulated ischemia buffer, containing 98.5 mM NaCl, $1.2 \mathrm{mM} \mathrm{MgSO}_{4}, 10 \mathrm{mM} \mathrm{KCl,} 1 \mathrm{mM} \mathrm{CaCl}$, $40 \mathrm{mM}$ sodium lactate and $20 \mathrm{mM}$ HEPES ( $\mathrm{pH}$ 6.8), and simulated reoxygenation buffer, containing $20 \mathrm{mM} \mathrm{HCO}_{3}$, $0.9 \mathrm{mM} \mathrm{NaH}_{2} \mathrm{PO}_{4}, 1 \mathrm{mMCaCl}_{2}, 1.2 \mathrm{mM} \mathrm{MgSO}_{4}, 20 \mathrm{mMHEPES}$, $5 \mathrm{mM} \mathrm{KCl}, 129.5 \mathrm{mM} \mathrm{NaCl}$ and $5.5 \mathrm{mM}$ glucose (pH 7.4), were prepared in advance. The medium of the NRCs was replaced with $1 \mathrm{ml}$ simulated ischemia buffer, incubated in a hypoxic chamber (humidified atmosphere $5 \% \quad \mathrm{CO}_{2} / 0 \% \quad \mathrm{O}_{2}$ balanced with $\mathrm{N}_{2}$ at $37^{\circ} \mathrm{C}$ ) for $3 \mathrm{~h}$, and then reoxygenated in a standard incubator for $2 \mathrm{~h}$ with reoxygenation buffer. The cells subjected to control conditions were cultured with normal Tyrode solution ( $\mathrm{pH} 7.4$; Beijing Leagene Biotech Co., Ltd., Beijing, China) in a humidified atmosphere of $5 \% \mathrm{CO}_{2} / 21 \% \mathrm{O}_{2}$ balanced with $\mathrm{N}_{2}$ at $37^{\circ} \mathrm{C}$ for $5 \mathrm{~h}$ (4). The cells were divided randomly into four groups: Control group, incubated with Tyrode solution during the entire experimental period; SI/R group, incubated with simulated ischemia buffer for $3 \mathrm{~h}$ hypoxia, followed by $2 \mathrm{~h}$ re-oxygenation; Vehicle group, subjected to $0.2 \%$ (v/v) dimethyl sulfoxide administration $30 \mathrm{~min}$ prior to SI/R; SI/R+GSRg3 group, subjected to GSRg3 (10 mM) administration $30 \mathrm{~min}$ prior to SI/R (5).

Cell viability. The cell viability was assessed using a Cell Counting Assay kit-8 (CCK-8, Beyotime Institute of Biotechnology) according to the manufacturer's instructions. The NRCs $(100 \mu \mathrm{l})$ were plated into 96 -well plates at a density of $1 \times 10^{5}$ cells/well, followed by $30 \mathrm{~min}$ pre-incubation with different concentrations of GSRg3 $(0.1-100 \mu \mathrm{M})$. Following treatment, the cells were exposed to $10 \mu \mathrm{l}$ CCK- 8 solution for a futher $2 \mathrm{~h}$ and the absorbance at $450 \mathrm{~nm}$ was measured using a microplate reader (ELx808; Bio-Tek Instruments, Winooski, VT, USA) (1).

Determination of apoptosis by flow cytometry. The apoptotic rate of the NRCs was determined by flow cytometry using annexin V-fluorescein isothiocyanate (FITC)/propidium iodide (PI) staining according to the manufacturer's instructions. Briefly, the NRCs were pretreated with $10 \mu \mathrm{M}$ GSRg 3 for $30 \mathrm{~min}$ followed by SI/R treatment. The cells were digested with trypsin 


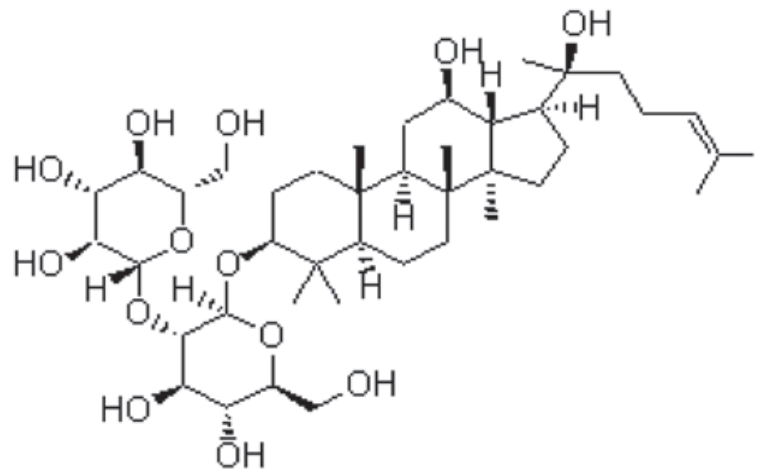

Figure 1. Chemical structure of ginsenoside $\mathrm{Rg} 3$. The molecular formula is $\mathrm{C}_{42} \mathrm{H}_{72} \mathrm{O}_{13}$ and the molecular weight is 785.01 .

$(0.25 \%)$ and were then resuspended in phosphate-buffered saline (PBS) containing 10\% NCS. The cells were centrifuged at $200 \mathrm{x}$ g for $10 \mathrm{~min}$ at $4^{\circ} \mathrm{C}$ and then washed twice with cold PBS. The cells were then treated with $5 \mu 1$ annexin V-FITC (1:80) and $10 \mu 1$ PI (1:40) (Bioworld Technology Co., Ltd., Nanjing, China), and incubated in the dark at room temperature for $15 \mathrm{~min}$. Each sample was analyzed using a Beckton-Dickinson flow cytometer (BD Biosciences, Franklin Lakes, NJ, USA).

Western blot analysis. The NRCs were lysed in lysis buffer (Beyotime Institute of Biotechnology) containing Protease Inhibitor Cocktail (Merck Millipore, Billerica, MA, USA) for $30 \mathrm{~min}$ on ice. The cellular proteins were collected using a cell scraper. Following centrifugation for $15 \mathrm{~min}$ at $12,000 \mathrm{rpm}$, a Bicinchoninic acid Protein Assay kit (Beyotime Institute of Biotechnology) was used to determine the protein concentrations. Equal quantities of protein were separated using $10 \%$ SDS-PAGE gels and transferred onto polyvinylidene fluoride membranes (EMD Millipore, Billerica, MA, USA). The membranes were blocked using $5 \%$ non-fat milk in Tris-buffered saline $(8 \mathrm{~g} \mathrm{NaCl}$ and $6 \mathrm{~g}$ Tris), containing 1\% Tween-20 (TBST), for $1 \mathrm{~h}$ at room temperature. The membranes were then incubated with primary antibodies against eNOS (610297; IgG1; polyclonal; 1:3,000; BD Biosciences), p-Akt (2920; mouse monoclonal; 1:1,000; Cell Signaling Technology, Inc., Danvers, MA, USA), Akt (4691; rabbit monoclonal; 1:1,000; Cell Signaling Technology, Inc.) Bcl-2 (2870; mouse polyclonal; 1:10000; Cell Signaling Technology, Inc.), Bax (2772; mouse polyclonal; 1:2,000; Cell Signaling Technology, Inc.) and PARP (5625; rabbit monoclonal; 1:1,000; Cell Signaling Technology, Inc.) overnight at $4^{\circ} \mathrm{C}$. Following washing three times for $5 \mathrm{~min}$ with TBST, the membranes were incubated with secondary antibodies, including alkaline phosphatase-linked anti-mouse (7056; $\mathrm{IgG}$; 1:5,000; Cell Signaling Technology, Inc.) or horseradish peroxidase-linked anti-rabbit antibodies at room temperature for $1 \mathrm{~h}$. $\beta$-actin $(7074$; $\operatorname{IgG}$; 1:5,000; Cell Signaling Technology, Inc.) was used as an internal control. The protein bands were visualized using a Chemiluminescence Electophoretic Mobility Shift Assay kit (Beyotime Institute of Biotechnology) and X-ray film (Kodak BioMax MS Film; Kodak. Corp., Rochester, NY, USA). The band density was statistically analyzed using Image J software (National Institutes of Health, Bethesda, MD, USA).
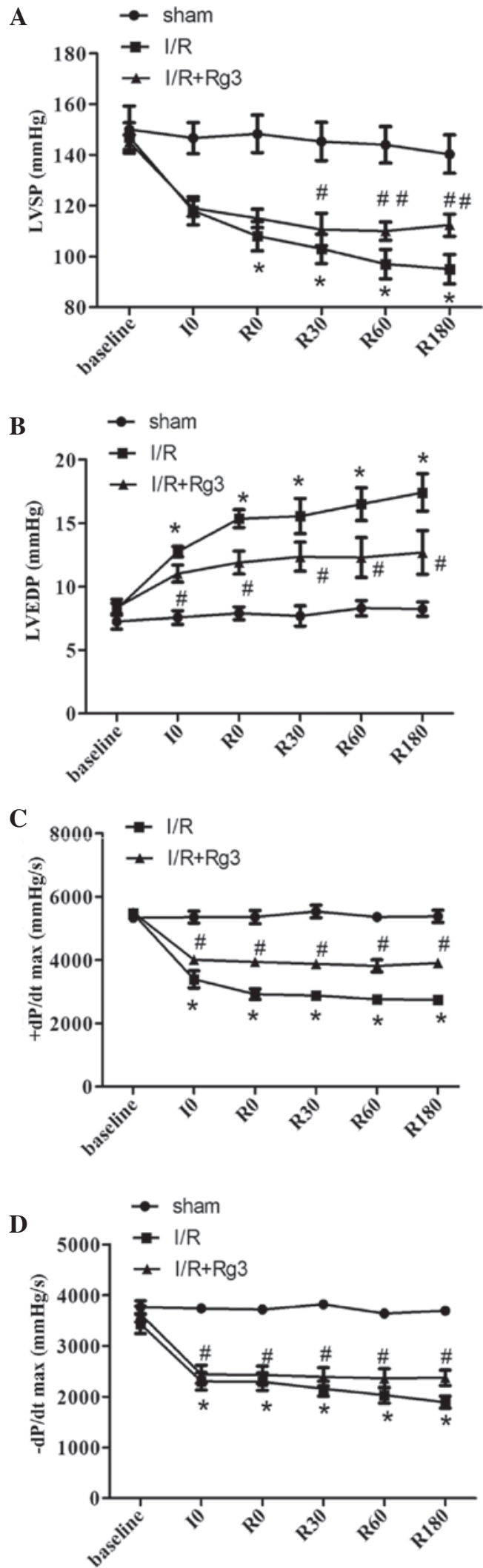

Figure 2. GSRg3 improves rat cardiac function following $30 \mathrm{~min}$ ischemia and $3 \mathrm{~h}$ reperfusion. Improvements were observed in (A) LVSP, (B) LVEDP, (C) $+\mathrm{dP} / \mathrm{dt}$ max and (D) $-\mathrm{dP} / \mathrm{dt}$ max. Data are expressed as the mean \pm standard error of the mean $\left(\mathrm{n}=8\right.$; ${ }^{*} \mathrm{P}<0.05$, vs. sham, ${ }^{\#} \mathrm{P}<0.05$ and ${ }^{\#} \mathrm{P}<0.01$, vs. I/R). LVSP, left ventricular systolic pressure; LVEDP, left ventricular end diastolic pressure; $\pm \mathrm{dP} / \mathrm{dt}$ max, instantaneous first derivation of left ventricle pressure; sham, untreated; I/R, ischemia/reperfusion; I/R+Rg3, I/R+Rg3 administration 3 days prior to surgery; baseline, immediately following stabilization; I0, pre-ischemic treatment; R0, start of reperfusion; R30, 30 min after reperfusion; R60, 60 min after reperfusion; R180, $180 \mathrm{~min}$ after reperfusion. GSRg3, ginsenoside Rg3. 


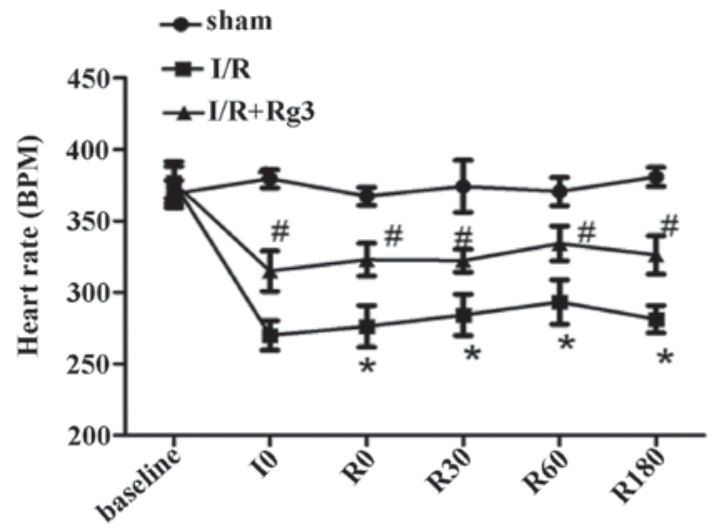

Figure 3. Changes in heart rate. Data are expressed as the mean \pm standard error of the mean $\left(\mathrm{n}=8 ;{ }^{*} \mathrm{P}<0.05\right.$, vs. sham, ${ }^{\#} \mathrm{P}<0.05$, vs. I/R). Sham, no treatment, I/R, ischemia/reperfusion; I/R+Rg3, I/R+Rg3 treatment 3 days prior to experimental surgery; baseline, immediately after stabilization; I0, pre-ischemic treatment; R0, start of reperfusion; R30, 30 min after reperfusion; R60, 60 min after reperfusion; R180, 180 min after reperfusion; GSRg3, ginsenoside $\operatorname{Rg} 3$

Statistical analysis. Data are expressed as the mean \pm standard error of the mean. The statistical comparisons between groups were performed using one-way analysis of variance. SPSS version 19.0 was used to perform all statistical analyses (SPSS Inc., Chicago, IL, USA). $\mathrm{P}<0.05$ was considered to indicate a statistically significant difference.

\section{Results}

Effect of GSRg3 on cardiac function. GSRg3 had no effect on blood glucose, cardiac function or blood pressure normality and no significant differences were observed between the groups at the baseline conditions. Pretreatment with GSRg3 increased LVSP and $+\mathrm{dp} / \mathrm{dt}$ max, and decreased LVEDP and -dp/dt max following $3 \mathrm{~h}$ reperfusion, compared with the MI/R group ( $\mathrm{P}<0.05$; Fig. 2). Treatment with GSRd markedly increased the mean heart rate compared with the $\mathrm{MI} / \mathrm{R}$ group $(\mathrm{P}<0.05$; Fig. 3$)$. The hemodynamic data demonstrated that GSRg3 improved rat cardiac systolic and diastolic function following MI/R.

GSRg3 reduced rat myocardial injury (infarct size, necrosis, and apoptosis) post MI/R. The infacted areas and areas at risk are shown in Fig. 4. No MI was observed in the hearts from the sham group. Pretreatment with GSRg3 significantly decreased the infarct size compared with the MI/R group $(\mathrm{P}<0.05)$. To determine whether GSRg3 attenuated MI/R induced cardiomyocyte necrosis, the plasma levels of CK, LDH and SOD were measured following reperfusion. GSRg3 treatment markedly decreased the levels of CK and LDH, and increased the levels of SOD compared with the MI/R group $(\mathrm{P}<0.05)$. These data demonstrated that GSRg3 reduced myocardial necrosis following MI/R.

GSRg3 improves SI/R-induced in vitro cell injury, increasing viability and decreasing apoptosis. The NRCs were treated with different concentrations of GSRg3 (0.1-100 mM) to determine the effects of GSRg3 alone. Treatment with these concentrations of GSRg3 for $24 \mathrm{~h}$ were not cytotoxic, as demonstrated by the CCK- 8 assay (Fig. 5A). As shown
A
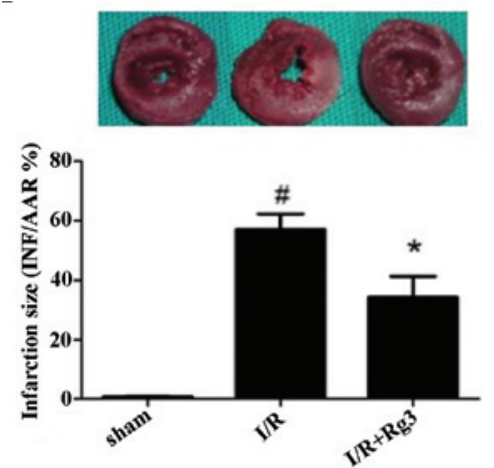

B

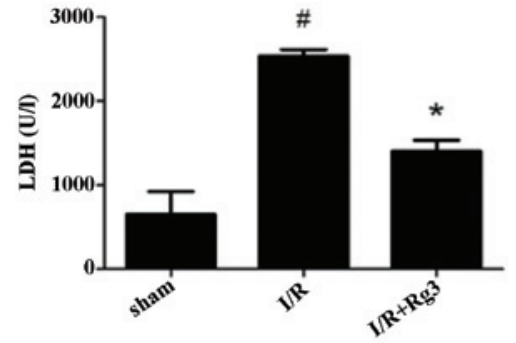

C

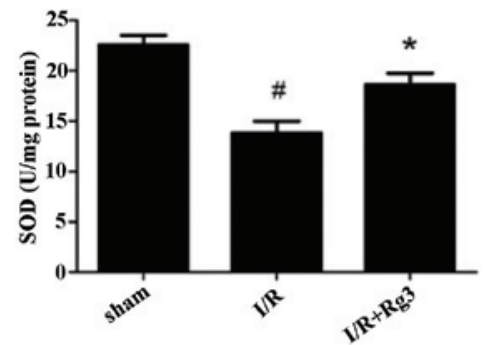

D

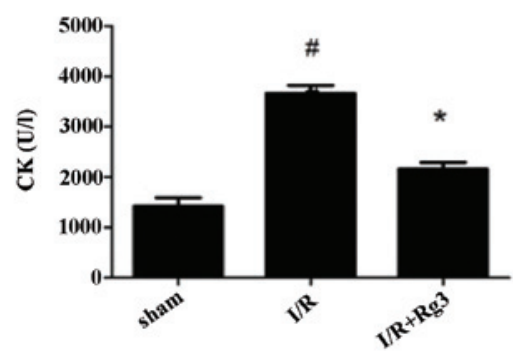

Figure 4. GSRg3 reduces rat myocardial injury (infarct size, necrosis, and apoptosis) post I/R. (A) INF in rats subjected to $30 \mathrm{~min}$ I, followed by $3 \mathrm{~h} \mathrm{R}$. Red-staining represents the AAR and pale areas indicate infracted regions. INF is expressed as a percentage of the AAR. (B) Plasma CK levels. (C) Plasma LDH levels. (D) Plasma SOD levels. Data are expressed as the mean \pm standard error of the mean $\left(n=6 ;{ }^{*} \mathrm{P}<0.05\right.$, vs. I/R, ${ }^{\text {" }} \mathrm{P}<0.05$, vs. sham $)$. $\mathrm{I} / \mathrm{R}$, ischemia/reperfusion; INF, myocardial infract size; AAR, area at risk; CK, creatine kinase; LDH, lactate dehydrogenase; SOD, superoxide dismutase; GSRg3, ginsenoside Rg3.

in Fig. 5B, the concentration response curves determined cellular viability, and this was observed at dosage of 10 mM GSRg3.

Flow cytometric analysis was perfomed to assess the cellular apoptosis (Fig. 5C). Annexin V/PI double staining revealed a significant increase in apoptosis in the sham group compared with the control post-SI/R $(8.6 \pm 0.3 \%$, vs. $3.1 \pm 0.2 \% ; \mathrm{P}<0.05)$, and treatment with $10 \mathrm{mM}$ GSRg3 markedly decreased cellular apoptosis $(4.6 \pm 0.1 \% ; \mathrm{P}<0.01$; Fig. 5D). Overall, these in vitro results suggested that GSRg3 protected cardiomyocytes, which was in accordance with the in vivo data. 

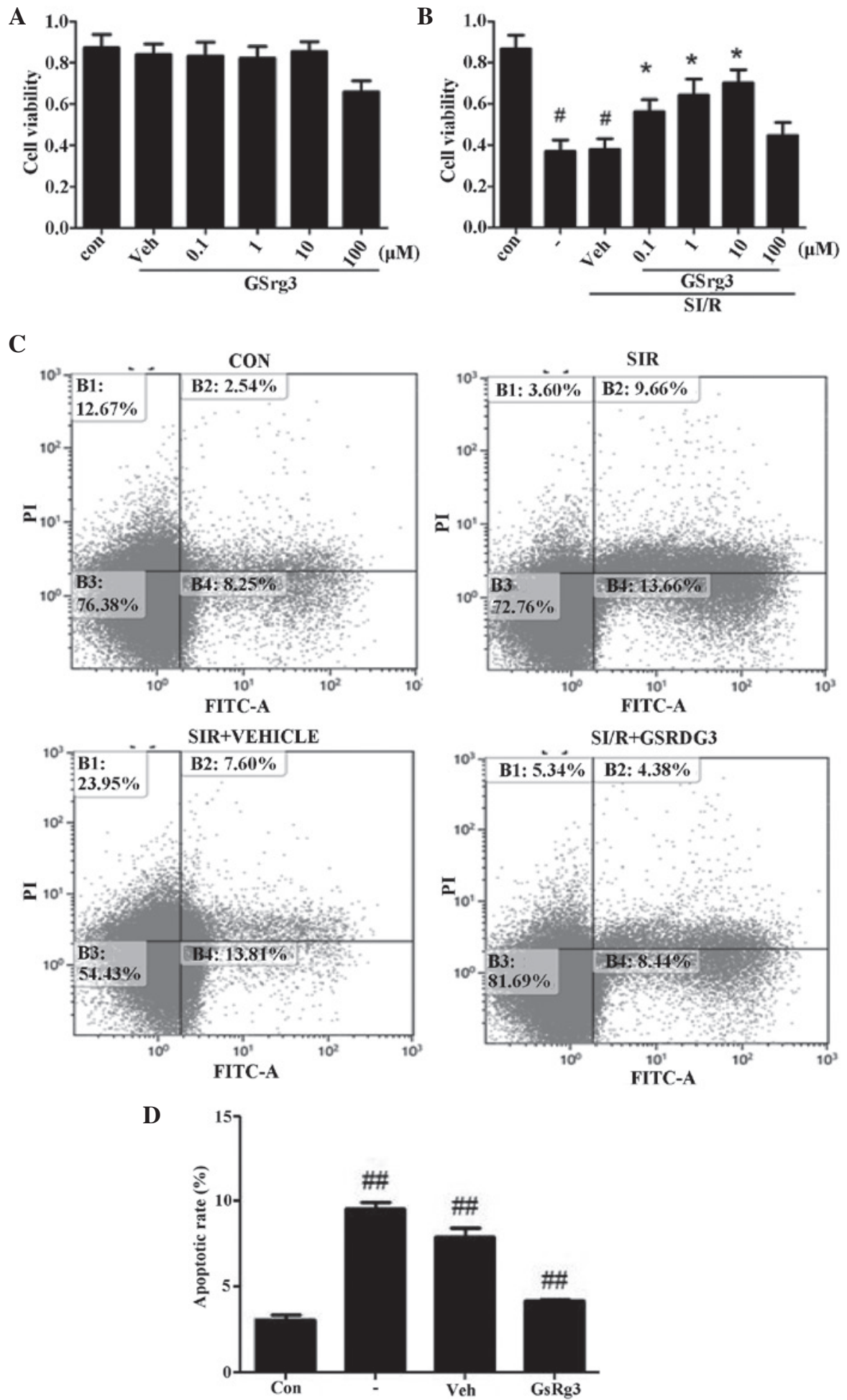

Figure 5. GSRg3 improves SI/R-induced in vitro cell injury (viability and apoptosis). (A) GSRg3 treatment alone (0.1-100 $\mu \mathrm{M})$ for $24 \mathrm{~h}$ had no effect on NRC viability, suggesting that no GSRg3-induced toxicity occurred at concentrations up to $10 \mu \mathrm{M}$ (n=8; $\mathrm{P}<0.05$, vs. control). (B) Cellular viability was determined using an MTT assay following SI/R (3 h hypoxia followed by $2 \mathrm{~h}$ reoxygenation). (C) SI/R-induced apoptosis was determined by annexin V-FITC/PI flow cytometry in control and vehicle groups. (D) GSRg3 $(10 \mathrm{mM})$ significantly reduced SI/R-induced apoptosis as determined by annexin V-FITC/PI flow cytometry. Data are expressed as the mean \pm standard error of the mean $\left({ }^{\#} \mathrm{P}<0.05\right.$ and ${ }^{\# \#} \mathrm{P}<0.01$, vs. control; ${ }^{*} \mathrm{P}<0.01$, vs. SI/R.) These experiments were performed in triplicate with similar results. SI/R, simulated ischemia/reperfusion; GSRg3, ginsenoside Rg3; NRC, neonatal rat cardiomyocyte; FITC, fluorescein isothiocyanate; PI, propidium iodide; Con, control; Veh, vehicle ( $0.2 \%$ (v/v) dimethyl sulfoxide treatment 30 min prior to SI/R).

GSRg3 modulates the expression levels of Bcl-2 and Bax in NRCs subjected to SI/R. The present study aimed to determine whether GSRg3 inhibited the apoptosis of NRCs induced by SI/R by modulating the Bcl-2 family proteins. SI/R treatment reduced the expression of $\mathrm{Bcl}-2$ and increased the expression of Bax, therefore, downregulating the Bcl-2/Bax ratio (Fig. 6A). Pretreating NRCs with $10 \mathrm{mM} \mathrm{GsRg} 3$ prior to SI/R induced the expression of $\mathrm{Bcl}-2$ and inhibited the expression of Bax, therefore, increasing the $\mathrm{Bcl}-2 / \mathrm{Bax}$ ratio (Fig. 6A). 
A
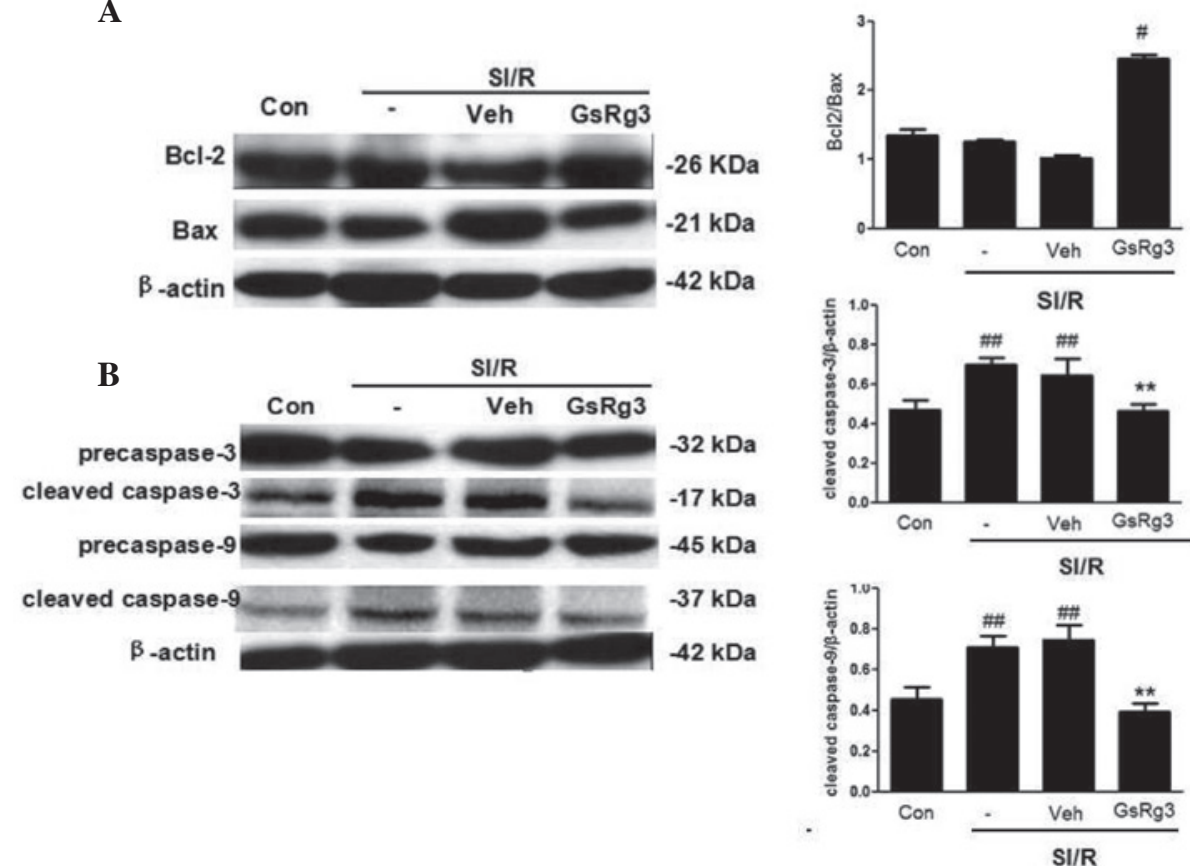

Figure 6. GSRg3 inhibits mitochondrial-mediated apoptosis in NRCs subjected to SI/R. (A) Representative western blot analysis demonstrating the expression of Bcl-2 and Bax following various treatments. Densitometric analysis demonstrated that SI/R reduced the ratio of Bcl-2/Bax, however, treatment with GSRg3 increased the Bcl-2/Bax ratio. (B) Representative western blot analysis of the SI/R-induced activation of caspase-3 and caspase-9. Densitometric analysis demonstrated that $10 \mathrm{mM} \mathrm{GSRg} 3$ reduced the expression levels of cleaved caspase- 9 and caspase- 3 . Data are expressed as the mean \pm standard error of the mean $\left(\mathrm{n}=6\right.$; ${ }^{\# \#} \mathrm{P}<0.01$, vs. control, ${ }^{\sharp} \mathrm{P}<0.05$ and ${ }^{* *} \mathrm{P}<0.01$, vs. SI/R.) SI/R, simulated ischemia/reperfusion; GSRg3, ginsenoside Rg3; NRC, neonatal rat cardiomyocyte; Bcl-2, B-cell lymphoma-2; Bax, Bcl-2 associated X protein; Con, control; Veh, vehicle (0.2\% (v/v) dimethyl sulfoxide treatment 30 min prior to SI/R).
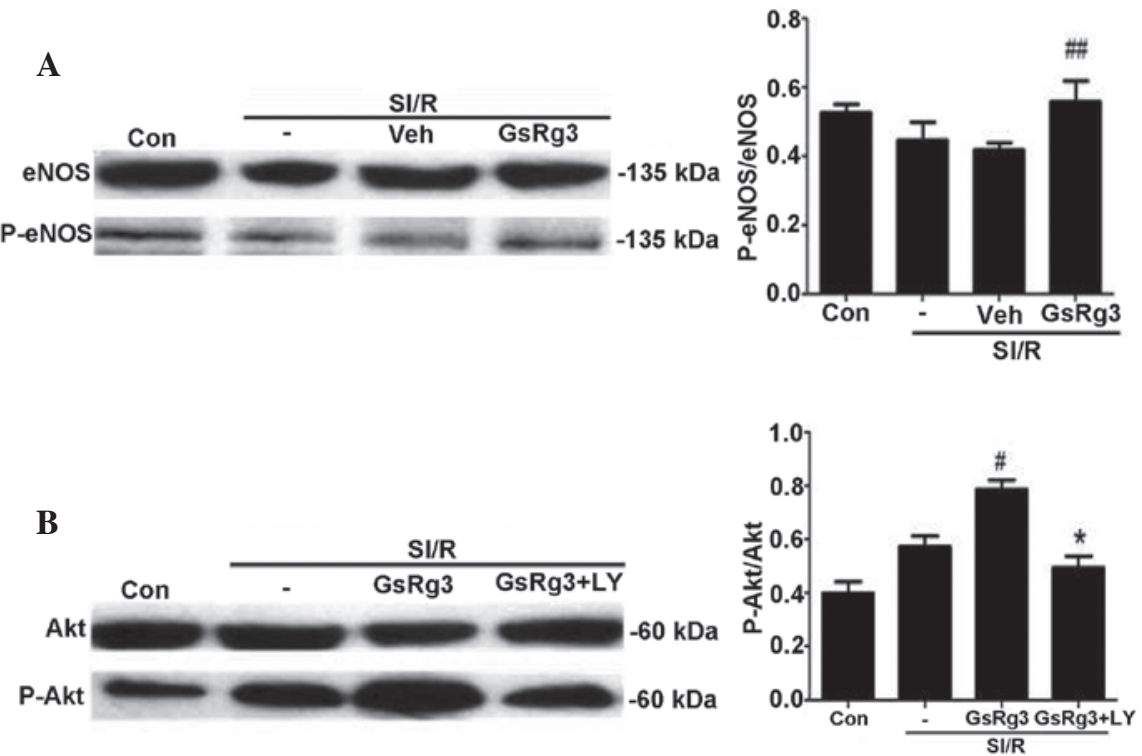

Figure 7. GSRg3 increases the phosphorylation of Akt and eNOS in NRCs subjected to SI/R. Densitometric analysis demonstrated that GSRg3 increased the ratio of (A) p-eNOS/eNOS and (B) p-Akt/Akt, and the increasing ratio of p-Akt/Akt was significantly inhibited by the Akt inhibitor, LY294002. Data are expressed as the mean \pm standard error of the mean ( $\mathrm{n}=6$; ${ }^{*} \mathrm{P}<0.05$ and ${ }^{\# \#} \mathrm{P}<0.05$, vs. SI/R; ${ }^{\mathrm{P}}<0.01$, vs. SI/R+GSRg3.) SI/R, simulated ischemia/reperfusion; GSRg3, ginsenoside Rg3; NRC, neonatal rat cardiomyocyte; eNOS, endothelial nitric oxide synthase; Con, control; Veh, vehicle( $0.2 \%$ (v/v) dimethyl sulfoxide treatment 30 min prior to $\mathrm{SI} / \mathrm{R}) ;$ p, phosphorylated.

GSRg3 decreases the activities of caspase-3 and caspase-9 in NRCs following SI/R. The caspase family of proteins regulate cellular apoptosis. Caspase-9 is activated by cytochrome $c$, which activates caspase-3, causing cell apoptosis (4). SI/R significantly increased the protein expression levels of cleaved caspase-9 and caspase-3, however, pretreating NRCs with
$10 \mathrm{mM} \mathrm{GsRg} 3$ significantly attenuated the expression levels of cleaved caspase-9 and caspase-3 (Fig. 6B).

GSRg3 increases the phosphorylation of Akt and eNOS in NRCs subjected to SI/R. To further investigate the molecular mechanism underlying GsRg3-mediated cardioprotection, 
western blot analysis was performed to determine the protein expression levels of phosphorylated (p)-Akt/Akt and p-eNOS in NRCs following SI/R. No significant differences were observed in the expression levels of Akt and eNOS between the treatment groups at the baseline (Fig. 7A and B). Consistent with previous reports, pretreatment with $10 \mathrm{mM} \mathrm{GSRg} 3$ significantly increased the expression levels of p-Akt and p-eNOS, and consequently increased the ratios of $\mathrm{p}$-Akt/Akt and $\mathrm{p}$-eNOS/eNOS $(\mathrm{P}<0.01)$. Treatment with the phosphoinositide 3-kinase inhibitor, LY294002, inhibited the GSRg3-mediated phosphorylation of Akt (Fig. 7B).

\section{Discussion}

The present study revealed that GSRg3 significantly attenuated $\mathrm{MI} / \mathrm{R}$ injury in the rat model, as demonstrated by the reduced myocardial infarct size, improved rat cardiac functions, $\mathrm{CK} / \mathrm{LDH}$ levels in blood following MI/R and decreased NRC apoptosis. The in vitro investigation revealed that treatment with GSRg3 (10 $\mathrm{mM})$ reduced the NRC apoptotic response by inhibiting the activation of caspase- 3 and caspase- 9 and by increasing the phosphorylation of Akt/eNOS and the Bcl-2/Bax ratio.

As one of the most popular Chinese herbal medicines, ginseng has been used for the treatment of diabetes, cancer and cardiovascular diseases for thousands of years $(7,8)$. Over 40 ginsenosides have been isolated and identified (9). Previous studies have demonstrated that ginsenosides exerts significant protective effects on the cardiovascular system (9-11). MI/R injury is predominantly caused by ardiomyocyte apoptosis (12) and GSRg3 is able to directly depress cardiomyocytes contraction by increasing the production of nitric oxide (NO) (13). Yang et al demonstrated that the NO produced by eNOS has a direct impact on cardiac remodeling (14). In addition, it has also been suggested that GSRg1 is important in the improvement of the cardiovascular system. In a tumor necrosis factor- $\alpha$ stimulated HUVEsl culture model, GSRg1 increases the production of NO and the mRNA expression of eNOS (15). In vitro, GSRg1 is capable of reducing homocysteine-induced endothelial dysfunction and free radical production in porcine coronary arteries (16-18). Therefore, the present study aimed to determine whether pretreatment with GSRg1 reduced myocardial infarction following MI/R, and whether this had significant clinical importance. A previous study suggested that GSRg1 may induce the production of NO and regulate the acute activation of eNOS in human aortic endothelial cells (19).

GSRg3, an important ginsenoside in the extract of ginseng, is used in herbal medicine as a tonic and restorative agent. However, the molecular mechanism underlying the beneficial effects of GSRg3 remains to be elucidated. The present study demonstrated, using an in vivo rat model, that pretreatment with GSRg3 significantly decreased the infarct size and plasma levels of $\mathrm{CK} / \mathrm{LDH}$. The levels of $\mathrm{CK} / \mathrm{LDH}$ and oxidative stress in the myocardium were also significantly suppressed in the GSRg3 treated group, whereas the level of SOD was improved. In vitro, $\mathrm{SI} / \mathrm{R}$ treatment increased the expression of Bax, a pro-apoptotic protein, decreased the expression of Bcl-2, an anti-apoptotic protein, reduced the Bcl-2/Bax ratio and activated caspase-3 and caspase-9. GSRg3 upregulated the phosphorylation of eNOS and increased the expression of p-Akt.

In conclusion, GSRg3 exerted cardioprotective effects in $\mathrm{MI} / \mathrm{R}$ injury and may have a positive significance for clinical treatment.

\section{References}

1. Terman A and Brunk UT: The effect of Polbax extract on lipofuscin accumulation in cultured neonatal rat cardiac myocytes. Phytother Res 16: 180-182, 2002.

2. Chlopcíková S, Psotová J, Miketová P, Sousek J, Lichnovský V and Simánek V: Chemoprotective effect of plant phenolics against anthracycline-induced toxicity on rat cardiomyocytes. Part II. caffeic, chlorogenic and rosmarinic acids. Phytother Res 18: 408-413, 2004.

3. Li SY, Wang XG, Ma MM, Liu Y, Du YH, et al: Ginsenoside-Rd potentiates apoptosis induced by hydrogen peroxide in basilar artery smooth muscle cells through the mitochondrial pathway. Apoptosis 17: 113-120, 2012.

4. Wang Y, Li X, Wang X, Gao F, et al: Ginsenoside Rd attenuates myocardial ischemia/reperfusion injury via Akt/GSK-3 $\beta$ signaling and inhibition of the mitochondria-dependent apoptotic pathway. PLoS One 8: e70956, 2013.

5. Zhu JH, Qiu YG, Wang QQ, Zhu YJ, Hu SJ, Zheng LG, et al: Low dose cyclophosphamide rescues myocardial function from ischemia-reperfusion in rats. Eur J Cardiothorac Surg 34: 661-666, 2008.

6. Li C, Gao Y, Tian J, Shen J, Xing Y, Liu Z, et al: Sophocarpine administration preserves myocardial function from ischemia-reperfusion in rats via NF- $\kappa$ B inactivation. J Ethnopharmacol 135:620-625, 2011.

7. Chang YS, Seo EK, Gyllenhaal C and Block KI: Panax ginseng: a role in cancer therapy? Integr Cancer Ther 2:13-33, 2003.

8. Attele AS, Zhou, Yuan CS, et al: Antidiabetic effects of Panax ginseng berry extract and the identification of an effective component. Diabetes 51:1851-1858, 2002.

9. Shi Y, Han B, Yu X, Qu S and Sui D: Ginsenoside Rb3 ameliorates myocardial ischemia-reperfusion injury in rats. Pharm Biol 49: 900-906, 2011.

10. Peng L, Sun S, Xie LH, Wicks SM and Xie JT: Ginsenoside Re: pharmacological effects on cardiovascular system. Cardiovasc Ther 30: e183-188, 2012.

11. Xia R, Zhao B, Wu Y, Hou JB, Zhang L, et al: Ginsenoside $\mathrm{Rb} 1$ preconditioning enhances eNOS expression and attenuates myocardial ischemia/reperfusion injury in diabetic rats. J Biomed Biotechnol 2011: 767930, 2011.

12. Ji L, Fu F, Zhang L, Liu W, Cai X, et al: Insulin attenuates myocardial ischemia/reperfusion injury via reducing oxidative/nitrative stress. Am J Physiol Endocrinol Metab 298: 871-880, 2010.

13. Scott GI, Colligan PB, Ren BH and Ren J: Ginsenosides Rb1 and Re decrease cardiac contraction in adult rat ventricular myocytes: role of nitric oxide. Br J Pharmacol 134: 1159-1165, 2001.

14. Yang XP, Liu YH, Shesely EG, Bulagannawar M, Liu F and Carretero OA: Endothelial nitric oxide gene knockout mice: cardiac phenotypes and the effect of angiotensinconverting enzyme inhibitor on myocardial ischemia/reperfusion injury. Hypertension 34: 24-30, 1999.

15. Lü JP, Ma ZC, Yang J, Huang J, Wang SR and Wang SQ: Ginsenoside $\mathrm{Rg} 1$-induced alterations in gene expression in TNF- $\alpha$-stimulated endothelial cells. Chin Med J (Engl) 117: 871-876, 2004.

16. Zhou W, Chai H, Lin PH, Lumsden AB, Yao Q and Chen C: Ginsenoside Rb1 blocks homocysteine-induced endothelial dysfunction in porcine coronary arteries. J Vasc Surg 41: 861-868, 2005.

17. Fu W, Conklin BS, Lin PH, Lumsden AB, Yao Q and Chen C: Red wine prevents homocysteine-induced endothelial dysfunction in porcine coronary arteries. J Surg Res 115: 82-91, 2003.

18. Spencer TA, Chai H, Fu W, et al: Estrogen blocks homocysteine-induced endothelial dysfunction in porcine coronary arteries $(1,2)$. J Surg Res 118: 83-90, 2004.

19. Yu J, Eto M, Akishita M, Kaneko A, Ouchi Y and Okabe T: Signaling pathway of nitric oxide production induced by ginsenoside Rb1 in human aortic endothelial cells: a possible involvement of androgen receptor. Biochem Biophys Res Commun 353: 764-769, 2007. 